\title{
OPTIMIZATION AND A COMPARISON BETWEEN RENEWABLE AND NON- RENEWABLE ENERGY SYSTEMS FOR A TELECOMMUNICATION SITE
}

\author{
Mohamed El Badawe, Tariq Iqbal and George K. Mann \\ Faculty of Engineering and Applied Science, Memorial University of Newfoundland \\ ${ }^{1}$ Corresponding author: m.elbadawe@mun.ca
}

\begin{abstract}
The renewable energy based hybrid energy system is the better solution to deal with environment pollution. It can also be used to provide power to stand alone applications, such as telecommunication sites, that are located in remote and rural areas. The aim of this paper is to optimize and compare a non-renewable energy system with a renewable energy system for a particular telecommunication site in Mulligan, Labrador, Canada. The current system works by using diesel generator and batteries and the proposed system is a combination of wind and solar with the existing diesel generator and batteries. Hybrid Optimization Model for Electric Renewable (HOMER) software is used to obtain the most feasible configuration of a hybrid renewable energy system. The results show the hybrid renewable energy system is more cost effective and better for the environment over the diesel generator because it reduces the running time of diesel generator and also reduce the emissions. It is expected that the proposed system and other similar configurations will help the Bell Aliant to provide uninterrupted power for their sites in remote areas of Labrador.
\end{abstract}

Index Terms - renewable energy systems; nonrenewable energy system; feasibility study; hybrid power systems; photovoltaic; wind turbine; diesel generator.

\section{INTRODUCTION}

The oil crises started in the beginning of 1970s, since that date the world has been experiencing the higher prices of the conventional fuel as well as negative impacts on the environment. In the last few years some oil countries reported that the fossil fuel started in depletion which is going to lead to a higher prices of oil. Moreover, the industrialized countries reported that the world already has seen many environmental issues such as toxic gases that produced from the fossil fuel after burned which will cause air pollution then global warming. Toxic gases such as sulfur oxides (SOX), nitrogen oxides (SOX), and the most dangerous one is carbon dioxide (CO2) because it is the main gas for greenhouse effect and it is not easy to control. On the other hand, the energy consumption around the world has been increasing while the fossil fuel has been decreasing. All the above reasons have led engineers and environments to find a sustainable and friendly environment solution and focus on renewable energy [1],[3],[6],[7].

Renewable energy is electricity supplied from renewable energy sources, and the renewable hybrid energy system is a system that contains two or more renewable energy sources. Renewable energy sources such as wind, solar, geothermal, tides, hydropower, and various forms of biomass. Wind and solar are the most interest areas in renewable energy these days. Renewable energy is very important to overcome the negative impacts on the environment and oil prices. Most importantly, renewable energy is very important to generate a power for remote communities and remote service places such as telecommunication repeaters [4], [5].

These alternative sources usually are integrated with diesel generator to provide a suitable reliability of the system to power loads. The most popular alternative sources are wind and Photovoltaic (PV), but they are seasonal sources which can't provide a continuous power to loads. Also, these power source produce fluctuating power. Therefore, diesel generator and batteries are using as a backup for long-term and short-term power storage respectively in most of remote areas applications [2],[4],[8].

The aim of this paper is to optimize and compare a non-renewable energy system (existing system) with a renewable energy system (proposed system) for a particular telecommunication site in Mulligan, Labrador, Canada. A non-renewable energy system currently is working by using diesel generator and batteries. Taking this system step further by adding renewable energy sources wind and photovoltaic to provide an uninterruptible power to remote telecommunication facilities, will lead to a reduction of diesel generator run times. This paper also shows the prefeasibility of the proposed hybrid renewable energy system and the results show the cost effectiveness of the proposed system.

\section{ELECTRICAL LOAD}

Data Synthesizer is used to generate the load data, and then use it in HOMER. The approximately power consumption at Mulligan site is $79.5 \mathrm{kWh} /$ day with $3.9 \mathrm{~kW}$ peak and the 
system runs on $48 \mathrm{~V}$ DC bus. Telecommunication companies are working very hard to provide an uninterruptable power to their sites and provided a service with high quality throughout the year. Therefore, the hourly load is almost a constant, as the power consumption remains same. Bell Aliant telecommunication site load profile is shown in figure 1 which is produced by HOMER.

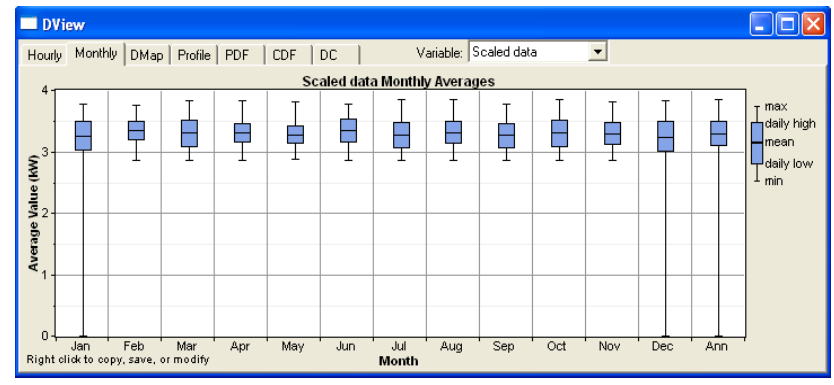

Figure 1. Load profile for Mulligan site

\section{RENEWABLE ENERGY RESOURCES}

The most important factor in developing the hybrid energy system is the location where is the system will be used. Choosing such a place depends on the availability of the renewable energy resources. Some resources are available in specific places for most of the time such as hydro, and some resources are available seasonally such as wind and photovoltaic. Canada has imense renewable energy recourse but at this particular place (Mulligan telecommunication site) wind and solar energy are abundantly available. Collecting weather data is one of the main task for this pre-feasibility study for a renewable energy system.

\subsection{Solar Energy Resource}

The latitude and longitude of Mulligan village are $53^{\circ} .86^{\prime} \mathrm{N}$ and $59^{\circ} .92^{\prime} \mathrm{W}$ respectively with time zone GMT3:30 Newfoundland. The hourly solar radiation data is collected for year from NASA website. The average solar irradiation is only $2.85 \mathrm{kWh} / \mathrm{m}^{2}$-d and sensitivity analysis is done with three different values. Clearness index and the average daily radiation for a year are shown in table I while figure 2 shows the solar radiation in a year produced by HOMER.

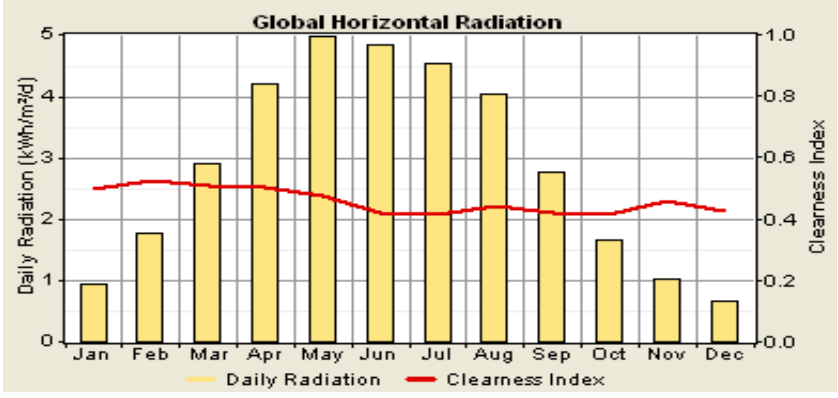

Figure 2. Monthly solar radiation
TABLE I. CLEARNESS INDEX AND AVERAGE DAILY IRRADIATION FOR A YEAR

\begin{tabular}{|l|l|l|}
\hline Month & Clearness Index & $\begin{array}{l}\text { Daily Radiation } \\
\left(\boldsymbol{k} \boldsymbol{W h} \mathbf{m}^{2}-\boldsymbol{d}\right)\end{array}$ \\
\hline January & 0.496 & 0.950 \\
\hline February & 0.525 & 1.760 \\
\hline March & 0.509 & 2.890 \\
\hline April & 0.502 & 4.200 \\
\hline May & 0.474 & 4.980 \\
\hline June & 0.421 & 4.830 \\
\hline July & 0.412 & 4.530 \\
\hline August & 0.442 & 4.040 \\
\hline September & 0.418 & 2.750 \\
\hline October & 0.412 & 1.660 \\
\hline November & 0.458 & 1.020 \\
\hline December & 0.427 & 0.650 \\
\hline
\end{tabular}

\subsection{Wind Energy Resource}

The second renewable source implemented in the system is wind. Wind data for this site is still under collection. So, scaling up the wind speed data from windatlas.ca is used to get the approximate wind speed at Mulligan's telecommunication site. Figure 3 shows the average hourly wind speed for a year. The average wind speed is estimated $6.261 \mathrm{~m} / \mathrm{s}$ and for sensitivity analysis three values of wind speed are chosen. The monthly average wind speed is shown in table II.

TABLE II. MONTHLY AVERAGE WIND SPEED FOR A YEAR

\begin{tabular}{|l|l|}
\hline Month & Wind Speed $(\boldsymbol{m} / \mathbf{s})$ \\
\hline January & 6.910 \\
\hline February & 6.500 \\
\hline March & 6.665 \\
\hline April & 6.256 \\
\hline May & 5.847 \\
\hline June & 5.970 \\
\hline July & 5.520 \\
\hline August & 5.561 \\
\hline September & 6.011 \\
\hline October & 6.338 \\
\hline November & 6.788 \\
\hline December & 6.788 \\
\hline
\end{tabular}




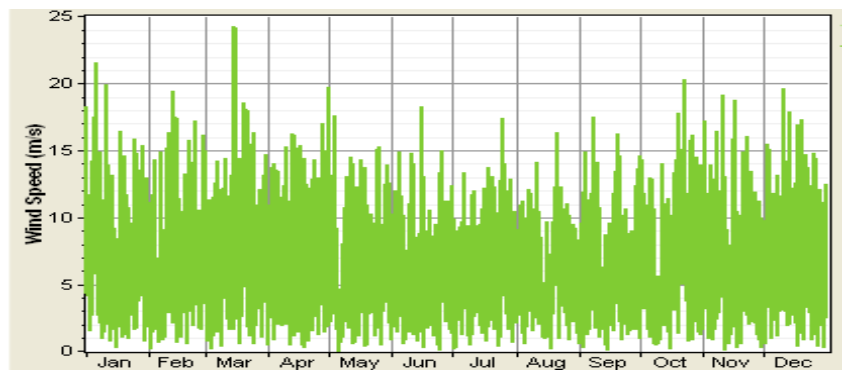

Figure 3 . The average hourly wind speed for a year

\section{SYSTEM OPTIMIZATION}

The non-renewable energy system (existing system) and the renewable energy system (proposed system) are simulated in Homer software.

\subsection{Non-Renewable Energy System}

The existing system architecture is shown in figure 4 which consists of a diesel generator and batteries to power the load. A Perkins $404 \mathrm{C}-22 \mathrm{G}$ diesel generator with $25 \mathrm{~kW}$ at $1800 \mathrm{rpm}$ is using there and the engine is rebuild every 15,000 hours. The initial capital cost is $\$ 16308$, replacement cost is $\$ 13590$, and operational and maintenance cost is $\$ 0.1 / \mathrm{hr}$. Two strings of VRLA GNB XL3000 batteries are using at Mulligan each battery is $2 \mathrm{~V}$ and has a capacity $3000 \mathrm{Ah}$ with $48 \mathrm{~V}$ total bus voltage. These batteries are replaced every 10 years. The initial capital cost, replacement coast, and maintenance and operation coast of all batteries are $\$ 86000, \$ 60000$, and $\$ 100$ respectively. A converter is included in order to maintain the flow of energy between the $\mathrm{AC}$ and the DC bus. The size of the convertor that is used in this system is $7 \mathrm{~kW}$. The initial capital cost and replacement cost are $\$ 2500$ and $\$ 1500$ respectively and maintenance and operation coast is $\$ 100$.

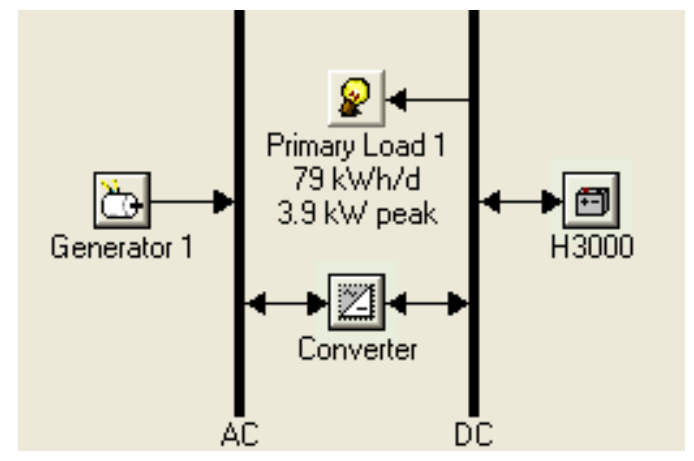

Figure 4. Existing power system at Mulligan

\subsection{Renewable Energy System}

The proposed hybrid renewable energy system is shown in figure 5 which consists of the existing power system, wind turbine, and photovoltaic. The proposed system is going to reduce diesel fuel consumption and associated operation and maintenance cost. In this system the wind turbines and PV will be the primary power source and diesel generator will be using as a backup for long term storage system and batteries for short term storage system.

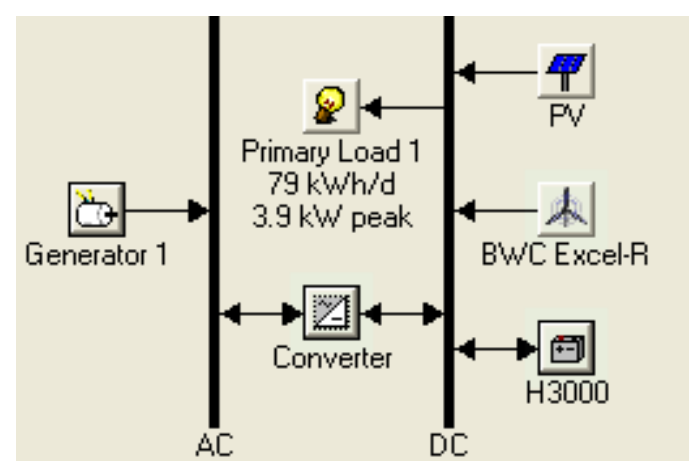

Figure 5. Proposed hybrid power system for Mulligan

\subsubsection{Solar Panels}

STP280-24/Vd solar modules are used in this system and each module panel provides $280 \mathrm{~W}$ with $24 \mathrm{~V}$. Therefore, two $\mathrm{PV}$ modules are connected in series to meet the bus voltage which is $48 \mathrm{~V}$. A total of $5.6 \mathrm{~kW}$ PV rated capacity is used in this system. Modules are connected in 10 strings each string has two modules with twenty modules in total. The initial cost of each two panels connected in series is $\$ 1745$, replacement cost is $\$ 1342$, and operational and maintenance cost is $\$ 52$.

\subsubsection{Wind Turbine}

Two BWC-Excel-R/48 are used in this system. Each one has rated capacity $7.5 \mathrm{~kW}$ and provides $48 \mathrm{~V}$ DC. The initial capital cost $\$ 23081$, replacement cost is $\$ 17000$, and annual operation and maintenance cost is $\$ 462$ for each one. The technical parameters of wind turbine are obtained from Bergey Windpower. The hub and anemometer are located at $30 \mathrm{~m}$ height.

\section{RESULTS AND DISSCUSSION}

Both systems are simulated in HOMER software, and the optimal results were obtained for each case. Figure 6 shows the optimization result for the non-renewable energy system. As shown in the figure the total Net Present Cost (NPC) is $\$ 823,072$. Diesel generator burns $12,672 \mathrm{~L}$ of fuel per year and annual generator run time is 1,536 hours. In twenty years the diesel generator will burn $25,3440 \mathrm{~L}$ of fuel. For this site the diesel fuel can be transported only by a helicopter. Therefore the total cost of diesel fuel at $\$ 5$ per liter, would be very high. The probability of fuel prices increase is also high. The total cost is calculated with constant price of fuel, which is $\$ 5$ per liter. The total fuel cost during these 20 years will be $\$ 1,267,200$ and the total 
cost for the whole system will be $\$ 2,090,272$. Figure 7 shows the monthly average electric production of the system which is totally produced by diesel generator.

\begin{tabular}{|c|c|c|c|c|c|c|c|c|c|}
\hline \multicolumn{10}{|c|}{ Sensitivity Results Optimization Results } \\
\hline \multicolumn{10}{|c|}{ Double click on a system below for simulation results. } \\
\hline 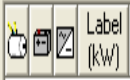 & H3000 & $\begin{array}{l}\text { Conv. } \\
\left(\mathrm{k} W \mid{ }^{\prime}\right)\end{array}$ & $\begin{array}{l}\text { Intitial } \\
\text { Copital }\end{array}$ & $\begin{array}{l}\text { Operating } \\
\operatorname{Cos}(\$ y y)\end{array}$ & $\begin{array}{l}\text { Total } \\
\text { NPC }\end{array}$ & $\left.\begin{array}{c}C O E E \\
(\$ \$ / k W h\end{array}\right)$ & \begin{tabular}{l|} 
Ren. \\
Frac.
\end{tabular} & $\begin{array}{l}\text { Diesel } \\
\text { (L) }\end{array}$ & $\begin{array}{l}\text { Label } \\
\text { (hrs }\end{array}$ \\
\hline 6因图 25 & 48 & 25 & $\$ 197,23$ & 65,172 & $\$ 823,0$ & 2.973 & 0.00 & 12,67 & 1,536 \\
\hline
\end{tabular}

Figure 6. Optimized result for the non-renewable energy system

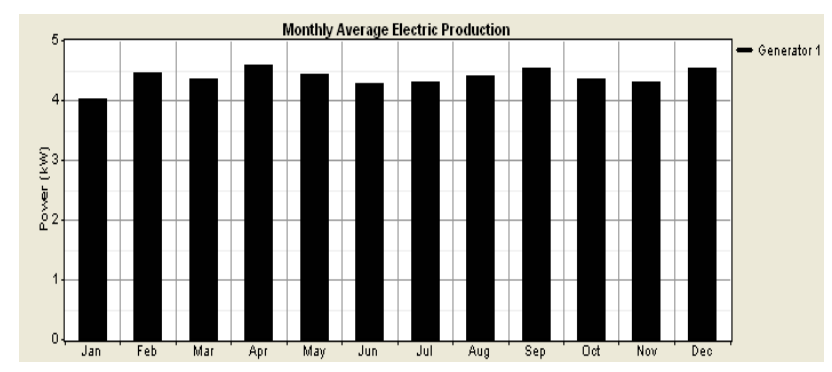

Figure 7. Monthly average electric production for non-renewable energy system

The renewable energy based system was also simulated in HOMER software with four sensitivity variables. These variables are wind speed, solar irradiation, load, and diesel price and each of these variables has three different values. Therefore, 81 sensitivity cases have been tested for the system. Figure 8 shows the optimized results for the proposed system. The total Net Present Cost (NPC) is $\$ 1,011,514$. The system will consume only 335 liters of diesel fuel per year and annual generator run time is expected to be 145 hours. The lifetime of this system is 25 years, but 20 years life is used to make the comparison between two systems. In twenty years the diesel generator will burn $6,700 \mathrm{~L}$ of fuel and it will cost $\$ 33,500$. The total cost of the system will be around $\$ 1,045,014$. Figure 9 shows the monthly average electric production of the system. Photovoltaic production is $14 \%$ with $6,403 \mathrm{kWh} / \mathrm{yr}$. Diesel generator production is $2 \%$ with $1,052 \mathrm{kWh} / \mathrm{yr}$. Finally, wind turbine is expected to supply the rest of the load which is $84 \%$ with $38,325 \mathrm{kWh} / \mathrm{yr}$.

The difference cost between two systems is $\$ 1,045,258$ which is a very significant number for a small system. Diesel generator run times are reduced and diesel generator in the proposed system will produce only $2 \%$ of the total power production. Moreover, the reduction of yearly diesel fuel consumption from $12,672 \mathrm{~L}$ to $335 \mathrm{~L}$ has a large impact on the environment and it will reduce the helicopter trips to the site. Also, the diesel generator will require less maintenance and operation cost and longer period of service before a replacement.

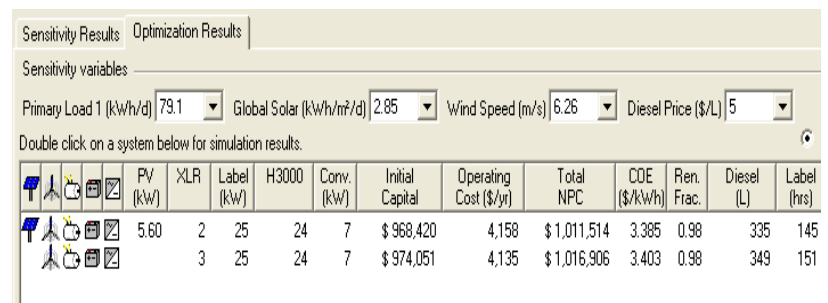

Figure 8. Optimized result for the renewable energy system

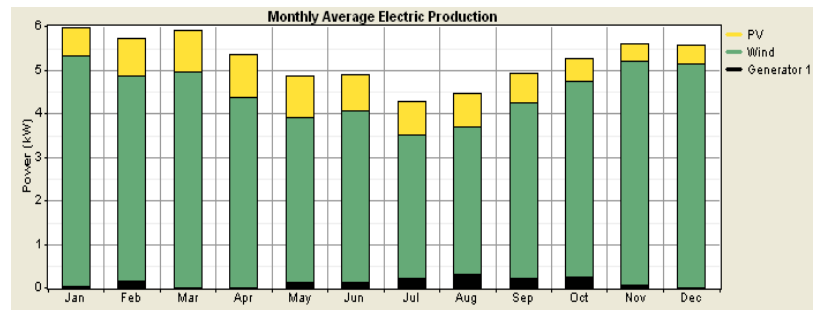

Figure 9. Monthly average electric production for renewable energy system

\section{CONCLUSION}

This paper compares two different systems for providing uninterruptible power for a telecommunication tower on a remote site. This comparison based on the pre-feasibility for each system is done using HOMER software. The first system is non-renewable energy system and the second is renewable energy system. The renewable energy based proposed system is a combination of wind and photovoltaic which is environment friendly system and it will save extra cost associated with transporting diesel and maintenance. Analysis indicates that a renewable energy system based will cost $\$ 1,011,514$ less in its expected life. Therefore, a renewable energy based hybrid system is recommended for Mulligan Labrador site.

\section{ACKNOWLEDGMENT}

The authors would like to thank Ministry of Education and Scientific Research of the Great Socialist People's Libyan for giving the corresponding author a scholarship to do his master degree at Memorial University of Newfoundland and Mr. Stephen Smith of Bell Aliant for providing the site load data, location, and configuration information.

\section{REFERENCES}

[1] Ross, M.; Hidalgo, R.; Abbey, C.; Joós, G.; , "Analysis of Energy Storage sizing and technologies," Electric Power and Energy Conference (EPEC), 2010 IEEE, vol., no., pp.1-6, 2527 Aug. 2010.

[2] M. Muralikrishna and V. Lakshminarayana.; "Hybrid (solar and wind) energy systems for rural electrification", ARPN Journal of Engineering and Applied Sciences, vol. 3, no. 5, october 2008.

[3] El Badawe, M.; Iqbal, T.; George,M.; "Optimal sizing and modeling of a hybrid energy system for a remote 
telecommunication facility" presented at IEEE 21, NECEC conference, St.John's NF, 2011.

[4] Reaz Ul Haque; M. T. Iqbal ; John E. Quaicoe ; "Sizing, dynamic modeling and power electronics of a hybrid energy system", Canadian Conference on Electrical and Computer Engineering, 2006. CCECE '06. , pp1135-1138, May 2006.

[5] Watada, J.; Yu-Lien Tai; Yingru Wang; Jaeseok Choi; Shiota, M.; , "Service cost optimization in supply balance of sustainable power generation," Technology Management in the Energy Smart World (PICMET), 2011 Proceedings of PICMET '11: , vol., no., pp.1-11, July 31 2011-Aug. 42011.

[6] Komerath, N.; Venkat, V.; Halka, M.; Soloway, D.; , "Micro renewable energy systems: Synergizing technology, economics and policy," Science and Innovation Policy, 2009 Atlanta Conference on, vol., no., pp.1-8, 2-3 Oct. 2009

[7] Smith, S.S.; Iqbal, M.T; , "Design and Control of a Hybrid Energy System for a Remote Telecommunication Facility ", presented at IEEE 17, NECEC conference, St.John's NF, 2007.

[8] El Badawe, M.; Iqbal, T.; George,M.; "Design and dynamic modeling of a hybrid street light system" presented at IEEE 21, NECEC conference, St.John's NF, 2011. 